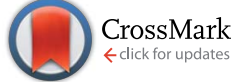

Cite this: RSC Adv., 2015, 5, 55588

\title{
Reactivation of lipases by the unfolding and refolding of covalently immobilized biocatalysts
}

\author{
Nazzoly Rueda,,$^{\mathrm{ab}}$ Jose C. S. dos Santos, $\hat{\dagger}^{\mathrm{ac}}$ Rodrigo Torres, $\dot{\dagger}^{\mathrm{b}}$ Oveimar Barbosa, ${ }^{d}$ \\ Claudia Ortiz $^{\star e}$ and Roberto Fernandez-Lafuente ${ }^{\star a}$
}

Lipases from Candida antarctica (isoform B) (CALB) and Thermomyces lanuginosus (TLL) have been immobilized either covalently or by interfacial activation versus an octyl support, followed by covalent attachment by glyoxyl groups using octyl-glyoxyl agarose beads (OCGLX). These biocatalysts have been submitted to successive cycles of unfolding by incubation in $9 \mathrm{M}$ guanidine and refolding by incubation in aqueous $100 \mathrm{mM}$ phosphate buffer at $\mathrm{pH} \mathrm{7,} \mathrm{before} \mathrm{and} \mathrm{after} \mathrm{total} \mathrm{inactivation} \mathrm{in} \mathrm{the} \mathrm{presence} \mathrm{of}$ organic solvents. The four preparations have been reactivated to some extent using this strategy, but the results depended on the method of preparation. Glyoxyl-immobilized CALB may recover 100\% of its activity versus $p$-nitrophenyl butyrate, but after solvent inactivation the recovery of activity was reduced to $95 \%$. The pure covalent TLL preparation recovered around $80 \%$ of its activity, either before or after solvent inactivation. Both enzymes showed less recovery of activity using OCGLX, as might be expected from the hydrophobic nature of the supporting groups (60\% for CALB and $45 \%$ for TLL). In addition, using enzymes previously inactivated by solvent, recovery decreased by $5-10 \%$. These values were maintained through three successive cycles. However, using $R$ - and $S$-methyl mandelate, it was clear that recovery of activity decreased with further reactivation cycles. Taken as a whole, the unfolding and refolding effect may be used to recover a degree of enzyme activity. This is relevant in terms of application, as it may allow the enzyme preparations to be used for a longer period. However, to reach a similar enzyme structure in each reactivation cycle, it will be necessary to undertake further studies involving the use of other supports in order to improve the unfolding and refolding steps.

Received 23rd April 2015 Accepted 15th June 2015

DOI: $10.1039 / \mathrm{c} 5 \mathrm{ra07379k}$

www.rsc.org/advances

\section{Introduction}

Enzymes are of interest as biocatalysts due to their high activity in aqueous media at low temperature and pressure, and in addition their high degree of enantio- and region-selectivity and specificity. ${ }^{1-7}$

Enzymes themselves have limitations, however, since their optimal physiological properties and the features required for their industrial implementation may in some respects be in conflict. ${ }^{8}$ This occurs for example with the relatively moderate

${ }^{a}$ ICP - CSIC, Campus UAM - CSIC, Cantoblanco, 28049 Madrid, Spain.E-mail: rfl@ icp.csic.es

${ }^{b}$ Escuela de Química, Grupo de investigación en Bioquímica y Microbiología (GIBIM), Universidad Industrial de Santander, Edificio Camilo Torres 210, CEP 680001, Bucaramanga, Colombia

'Departamento de Engenharia Química, Universidade Federal Do Ceará, Campus Do Pici, CEP 60455-760, Fortaleza, CE, Brazil

${ }^{d}$ Grupo de investigación en productos naturales (GIPRONUT), Departamento de Química, Facultad de Ciencias, Universidad del Tolima, Ibagué, Colombia

${ }^{e}$ Escuela de Microbiología, Universidad Industrial de Santander, Bucaramanga, Colombia.E-mail: ortizc@uis.edu.co

$\uparrow$ Nazzoly Rueda and Jose C. S. dos Santos contributed equally to this paper.

\$ Current address: Laboratorio de Biotecnología, Instituto Colombiano del Petróleo - Ecopetrol, Piedecuesta, Bucaramanga, Colombia. stability of enzymes under conditions very different from those encountered physiologically, and these are often the ones required by industry. ${ }^{\mathbf{9}, 10}$ Operational enzyme stability may be improved by genetic tools, ${ }^{11}$ chemical modification (e.g. crosslinking of the enzyme surface) ${ }^{\mathbf{1 2 , 1 3}}$ enzyme immobilization (e.g. generation of adequate nano-environments or by multipoint or multi-subunit immobilization) ${ }^{\mathbf{1 4 - 1 8}}$ or by selecting more suitable reaction conditions. ${ }^{19}$

Enzyme immobilization is a requirement in a number of industrial applications, ${ }^{20}$ and this is similar to other strategies of enzyme stabilization. ${ }^{\mathbf{1 3 , 1 8 , 2 1 , 2 2}}$ In addition, the operational stability of a biocatalyst may be further improved if a deactivated biocatalyst is later submitted to a reactivation procedure. ${ }^{23}$ If the enzyme is incubated in the presence of an inert organic solvent at neutral $\mathrm{pH}$ and moderate temperature, the enzyme is deactivated mainly through the promotion of inappropriate structures. In these cases, if the enzyme is submitted to an unfolding/refolding strategy, it may then be possible to recover its original structure. ${ }^{24}$

Some recent papers suggest that previous immobilization of the enzymes on supports via covalent linkages may help the refolding step. ${ }^{25-28}$ Together with the simplification promoted by the use of immobilized enzymes, immobilization prevents 
the enzyme aggregation during the unfolding/refolding process, and if several enzyme-support linkages are established, the refolding may be facilitated since the relative positions of these groups cannot be altered, and these may act as reference points during refolding. ${ }^{29}$ The main requirements of this strategy are that the enzyme molecules should remain attached to the support throughout the entire protocol, and that the support is sufficiently inert to avoid undesired enzyme-support interactions. Surprisingly, even fully chemically aminated enzymes can be refolded after immobilization by multipoint covalent attachment. ${ }^{29,30}$

Some examples of reactivation of immobilized enzymes involve lipases. ${ }^{26,29-31}$ These enzymes have an unusual mechanism of action, so-called interfacial activation, which requires some movement of the enzyme structure between a closed structure, with a polypeptide chain (known as a lid) blocking the active center, and an open structure, with the active center exposed to the medium..$^{32-36}$ In many cases the open lipase form is the only active form, and this has a tendency to become adsorbed on hydrophobic surfaces. ${ }^{37}$ The lid may have different configurations; in the case of the popular lipase from Candida antarctica (form B) (CALB) the lid is very small and does not fully isolate the active center from the medium, ${ }^{38}$ but CALB is still able to be adsorbed on hydrophobic surfaces. ${ }^{39}$ In other cases, such as the lipase from Bacillus thermocatenulatus, the enzyme has a double lid. ${ }^{\mathbf{4 0}}$ However, lipases usually have a large single lid, able to fully prevent the interaction of the enzyme active center and the medium, as in the case of the lipase from Thermomyces lanuginosus (TLL). ${ }^{41}$

On the other hand, a very useful strategy for immobilizing lipases is the interfacial activation of the enzyme on octyl agarose. ${ }^{\mathbf{4 2 , 4 3}}$ This strategy has enabled one-step immobilization/ purification/hyperactivation/stabilization of many lipases. ${ }^{\mathbf{4 4}}$ However, this immobilization protocol is not compatible with unfolding/refolding reactivation strategies, since the immobilization is reversible; ${ }^{44}$ indeed, the incubation of the lipase immobilized on this support in solutions containing a high concentration of guanidine is a technique used to recover the support after enzyme inactivation. ${ }^{44}$ However, a new heterofunctional support has recently been proposed, namely, octylglyoxyl agarose. ${ }^{45}$ This support couples the advantages of octyl agarose with those of the covalent attachment, making the immobilization irreversible. These new biocatalysts are usually even more stable than standard octyl-lipase biocatalysts. ${ }^{45}$ On the other hand there is a drawback, in that since this support makes immobilization irreversible, the support cannot therefore be reused after enzyme inactivation. However, it may now be possible to submit the immobilized enzyme to unfolding/ refolding reactivation strategies without risk of enzyme desorption, making it unnecessary to discard either the enzyme or the support. ${ }^{45}$ An ongoing problem is the possibility of interaction of the hydrophobic groups of the enzyme with the octyl groups of the support during refolding, which might inhibit the full reactivation of the enzyme.

In the current study the reactivation possibilities of CALB and TLL covalently immobilized on standard supports (glyoxyl or cyanogen bromide), or immobilized on octyl-glyoxyl supports, have been studied and compared. CALB is the lipase most utilized in the literature and has a number of applications. ${ }^{46,47}$ It presents a very small lid, ${ }^{38}$ whereas TLL is also widely utilized ${ }^{48}$ but has a large lid. ${ }^{41}$

\section{Materials and methods}

\subsection{Materials}

Solutions of CALB (6.9 $\mathrm{mg}$ of protein per $\mathrm{mL}$ ) and TLL (36 $\mathrm{mg}$ of protein per $\mathrm{mL}$ ) were a kind gift from Novozymes (Spain). Cyanogen bromide-crosslinked $4 \%$ agarose (CNBr) beads and octyl-agarose beads were obtained from GE Healthcare. $R$ - and $S$-methyl mandelate and $p$-nitrophenyl butyrate ( $p$-NPB) were supplied by Sigma Chemical (St Louis, MO, USA). All reagents and solvents were of analytical grade. Octyl-glyoxyl and glyoxylagarose were prepared as described previously. ${ }^{45,49}$

\subsection{Standard determination of enzyme activity}

The assay was performed by measuring the increase in absorbance at $348 \mathrm{~nm}$ produced by $p$-nitrophenol released by the hydrolysis of $0.4 \mathrm{mM}$-NPB in $100 \mathrm{mM}$ sodium phosphate at $\mathrm{pH}$ 7.0 and $25{ }^{\circ} \mathrm{C}\left(\varepsilon\right.$ under these conditions is $\left.5150 \mathrm{M}^{-1} \mathrm{~cm}^{-1}\right)$. To start the reaction, $50-100 \mu \mathrm{L}$ of lipase in solution or suspension were added to $2.5 \mathrm{~mL}$ of substrate solution. One international unit of activity (U) was defined as the amount of enzyme able to hydrolyze $1 \mu \mathrm{mol}$ of $p$-NPB per min under the conditions described previously. Protein concentration was determined using Bradford's method, ${ }^{28}$ and bovine serum albumin was used as reference.

\subsection{Immobilization of enzymes}

2.3.1 Immobilization of enzymes on octyl-glyoxyl (OCGLX) supports. The immobilization was performed using 1 or $5 \mathrm{mg}$ of protein per $\mathrm{g}$ of wet support. Commercial samples of the enzymes were diluted with the corresponding volume of $5 \mathrm{mM}$ sodium phosphate at $\mathrm{pH} 7$ and the OCGLX support was then added. ${ }^{45}$ The activity of both supernatant and suspension was followed using $p$-NPB. After immobilization the suspension was filtered and the supported enzyme washed several times with distilled water. The washed immobilized enzyme was then resuspended at $\mathrm{pH} 10$ for $12 \mathrm{~h}$, to favor the covalent enzymesupport reaction..$^{50}$

2.3.2 Immobilization of enzymes on a glyoxyl (GLX) support. Immobilization was performed as above (Section 2.3.1). The enzymes were diluted with $50 \mathrm{mM}$ sodium bicarbonate buffer at $\mathrm{pH} 10$ and the support was then suspended in the enzyme solution under gentle stirring. Samples of the supernatant and suspension were periodically withdrawn and the enzyme activity measured as described above.

2.3.3 Reduction with sodium borohydride. To terminate the covalent enzyme-support reaction, solid sodium borohydride was added to the OCGLX and GLX suspensions at a concentration of $1 \mathrm{mg} \mathrm{mL}^{-1}$ at $\mathrm{pH} 10$, and stirred gently for 30 min. This treatment reduces reversible Schiff's bases to stable secondary amino-bonds, and unreacted aldehyde groups to fully inert hydroxyl groups. ${ }^{4-51}$ The preparations were washed 
with CTAB (TLL) or Triton (CALB) to eliminate non-covalently attached enzyme molecules. The biocatalysts were finally filtered, washed with abundant distilled water and stored at $4{ }^{\circ} \mathrm{C}$.

2.3.4 Immobilization of enzymes on a BrCN support. TLL could not be immobilized on glyoxyl agarose, as the enzyme was not sufficiently stable at $\mathrm{pH} 10,^{29,48}$ and for this reason an alternative support was adopted. A volume of $2 \mathrm{~mL}$ of commercial TLL was diluted in $60 \mathrm{~mL}$ of $5 \mathrm{mM}$ sodium phosphate at $\mathrm{pH} 7$ and $6 \mathrm{~g}$ of wet $\mathrm{BrCN}$ support was then added. After gentle stirring for $90 \mathrm{~min}$ at $4{ }^{\circ} \mathrm{C}$, around $45 \%$ of lipase had become immobilized on the support. Immobilization of the enzyme support was terminated by incubating the biocatalyst with $1 \mathrm{M}$ ethanolamine at $\mathrm{pH} 8$ for $2 \mathrm{~h}$. Finally, the immobilized preparation was washed with abundant distilled water and stored at $4{ }^{\circ} \mathrm{C}$.

\subsection{Inactivation of different enzyme preparations in the presence of organic co-solvents}

Enzyme preparations were incubated in mixtures of $90 \%(\mathrm{v} / \mathrm{v})$ dimethylformamide (DMF) (for CALB), or $80 \%$ (v/v) 1,4dioxane (for TLL), with $100 \mathrm{mM}$ Tris- $\mathrm{HCl} \mathrm{pH} 7$ at $30^{\circ} \mathrm{C}$. Samples were withdrawn periodically and activity measured using $p$-NPB as described above. The organic co-solvents present in the samples had no significant effect during determination of enzyme activity (results not shown).

\subsection{Incubation in sodium guanidine}

Immobilized CALB and TLL biocatalysts were incubated in $9 \mathrm{M}$ guanidine at $25{ }^{\circ} \mathrm{C}$ for $12 \mathrm{~h}$. The biocatalysts were then filtered off and washed with $100 \mathrm{mM}$ sodium phosphate buffer at $\mathrm{pH} 7.0$ to remove the denaturant, and then re-suspended in a similar volume of aqueous $100 \mathrm{mM}$ sodium phosphate buffer at $\mathrm{pH}$ 7.0. Activity was determined periodically over $24 \mathrm{~h}$.

\subsection{Determination of the hydrolysis of $R$ - and $S$-methyl mandelate}

Enzyme activity was also determined using $R$ - or $S$-methyl mandelate. A mass of $200 \mathrm{mg}$ of the immobilized preparations was added to $1 \mathrm{~mL}$ of $50 \mathrm{mM}$ substrate in $50 \mathrm{mM}$ sodium phosphate at $\mathrm{pH} 7$ and $25{ }^{\circ} \mathrm{C}$ under continuous stirring. The degree of conversion was analyzed by RP-HPLC (Spectra Physic SP 100 coupled with a Spectra Physic SP 8450 UV detector) using a Kromasil C18 $(15 \mathrm{~cm} \times 0.46 \mathrm{~cm})$ column. Samples $(20 \mu \mathrm{L})$ were injected and eluted at a flow rate of $1.0 \mathrm{~mL} \mathrm{~min}{ }^{-1}$ using acetonitrile and $10 \mathrm{mM}$ ammonium acetate $(35: 65, \mathrm{v} / \mathrm{v})$ at $\mathrm{pH}$ 2.8 as the mobile phase; UV detection was performed at $230 \mathrm{~nm}$. The acid and ester had retention times of 2.4 and $4.2 \mathrm{~min}$, respectively. One unit of enzyme activity was defined as the amount of enzyme necessary to produce $1 \mu \mathrm{mol}$ of mandelic acid per min under the conditions described. Activity was determined in triplicate and showed maximum conversion of $20-30 \%$, and the data are given as average values.

\section{Results}

\subsection{Unfolding and refolding of immobilized TLL and CALB}

Fig. 1 shows that GLX-CALB submitted to three consecutive cycles of unfolding and refolding steps recovered $100 \%$ of the initial activity versus $p$-NPB. Reactivation was very rapid, and in $1 \mathrm{~h}$ enzyme had fully recovered its initial activity. Using OCGLXCALB, the situation was not so positive, however. In this case reactivation recovered $60 \%$ of the initial activity in the first cycle, and the reactivation was slower than that using GLX. After the third cycle the reactivation had risen to only $55 \%$ of the initial enzyme activity.

These results point to the fact that, in the nature of immobilization on GLX supports, GLX-CALB involved a multipoint attachment $^{50}$ and provided a fully inert surface, permitting rapid and almost complete refolding of the enzyme. The multipoint covalent attachment provided reference points to allow the enzyme to refold properly, ${ }^{29}$ and the inert surface avoided any unwanted enzyme-support interactions that could stabilize different enzyme structures. Using OCGLX, reactivation was slower and reached only $60 \%$ of the initial activity. This may have been due mainly to interaction between unfolded enzyme structures and the octyl groups of the support during refolding. Even though we were unable to fully recover the enzyme activity, OCGLX-CALB did in fact recover a considerable proportion of the activity in a consistent manner, which represented another advantage of the new preparation when compared to octyl supports alone, in which all the enzyme molecules are released from the support when incubated under unfolding conditions (results not shown).

Fig. 2 illustrates the results using TLL. Due to its low stability at $\mathrm{pH} 10,{ }^{29,48}$ this enzyme could not be immobilized on GLX, and $\mathrm{BrCN}$-agarose was therefore used as a standard covalent reference in our study. This preparation enabled the recovery of around $82 \%$ of enzyme activity, reactivation taking several hours. In the third cycle, the reactivation enabled the recovery of $78 \%$ of enzyme activity, similar to the values obtained in the first cycle. Using OCGLX-TLL, a lower percentage of initial enzyme activity was again recovered, the three cycles ranging

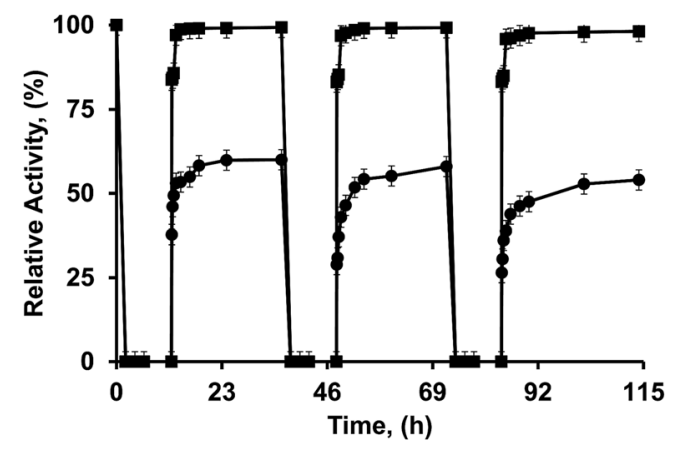

Fig. 1 Cycles of unfolding and refolding of different biocatalysts from CALB. Unfolding was carried out by incubation in $9 \mathrm{M}$ guanidine, and refolding by incubation in aqueous $100 \mathrm{mM}$ sodium phosphate. Experiments were performed as described in Section 2. Circles indicate OCGLX and squares GLX. 
between 45 and $48 \%$. Reactivation was slower than using BrCNTLL. These results suggested that the refolding of TLL may be more complex than that of CALB, which agrees with earlier reports in which the addition of certain detergents improved the reactivation. ${ }^{31}$

\subsection{Reactivation of immobilized TLL and CALB}

We next examined the possibility of using this strategy to reactivate enzyme that had been inactivated by the action of organic solvents. If we were able to fully unfold the enzyme structure, the results were expected to be similar to those obtained after unfolding and refolding the unaltered immobilized enzyme.

Fig. 3 shows that, after full inactivation in the presence of $90 \%$ DMF (v/v), reactivation of GLX-CALB allowed recovery of $95 \%$ of enzyme activity in the first cycle and $90 \%$ in the third, and the reactivation was slower than that indicated in Fig. 1. The results using OCGLX-CALB were similar, although in this case reactivation was only $50 \%$ in the first cycle and $45 \%$ in the third, compared with $60 \%$ observed using the unaltered enzyme. In addition, the operational life of the OCGLXimmobilized enzyme increased, but this may have been due in part to the non-reversibility of immobilization using this support.

Reactivation of BrCN-TLL allowed us to recover similar values of activity after enzyme inactivation in the presence of $80 \%$ dioxane (v/v) (Fig. 4) to those obtained when the unaltered enzyme was used (Fig. 2). Around $80 \%$ of enzyme activity was recovered during three successive inactivation and reactivation cycles. However, using OCGLX-TLL results (Fig. 4), the response differed from that in Fig. 2. Reactivation recovered only about $40 \%$ of the initial activity, and this value was maintained during the three cycles.

The results comparing the unaltered immobilized enzyme and the inactivated enzymes were not identical, with the exception of BrCN-TLL. Using GLX-CALB, the probable explanation was that we could not fully unfold this multipoint immobilized enzyme, even in $9 \mathrm{M}$ guanidine, and therefore the structures adopted by the enzyme when refolding began were not identical and led to changed final structures. The presence

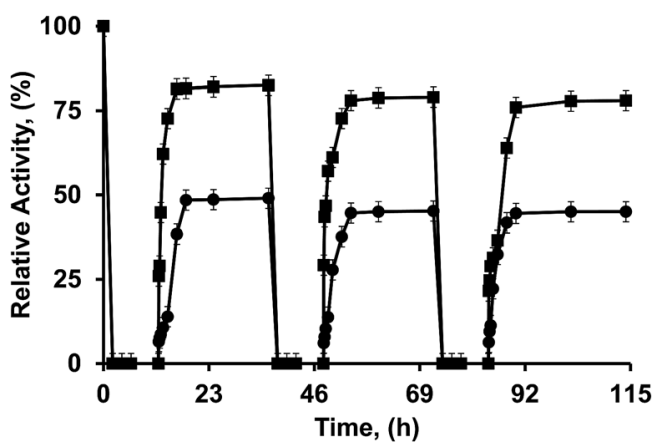

Fig. 2 Cycles of unfolding and refolding of different biocatalysts from TLL. Unfolding was carried out by incubation in $9 \mathrm{M}$ guanidine and refolding by incubation in an aqueous medium. Experiments were conducted as described in Section 2. Circles: OCGLX, squares: BrCN.

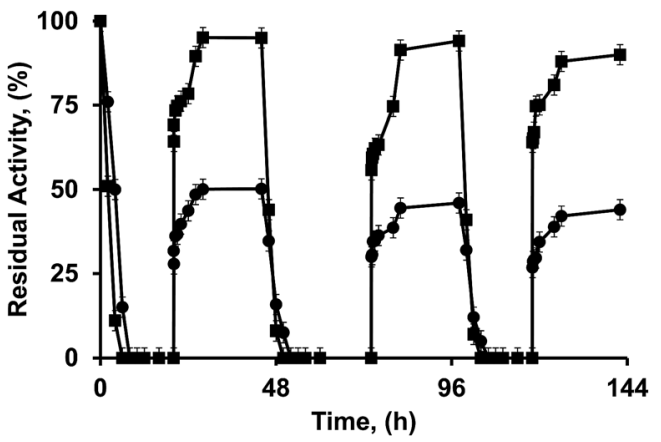

Fig. 3 Cycles of enzyme inactivation by incubation in 90\% DMF and reactivation by incubation in $9 \mathrm{M}$ guanidine, and refolding of different biocatalysts from CALB in an aqueous medium. Experiments were performed as described in Section 2. Circles: OCGLX, squares: GLX.

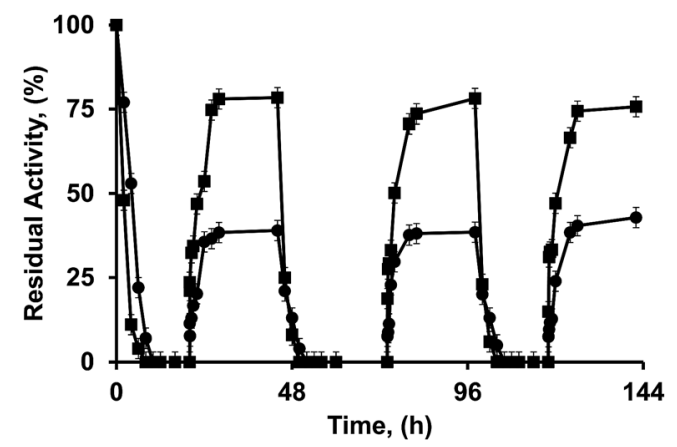

Fig. 4 Cycles of enzyme inactivation by incubation in $80 \%$ dioxane and reactivation due to unfolding by incubation in $9 \mathrm{M}$ guanidine and refolding by incubation in aqueous media of different biocatalysts from TLL. Experiments were performed as described in Section 2. Circles: OCGLX, squares: BrCN.

of large octyl groups, and the attachment of the enzyme by very short spacer arms, may have been additional factors in the unfolding and refolding steps of reactivation. A plausible explanation for the good results using BrCN-TLL was that this preparation had very few enzyme-support attachments (quite possibly just one) and the unfolding and refolding process was therefore much less likely to have been hampered by interaction with the support.

\subsection{Activity of differently treated CALB and TLL immobilized enzymes versus $R$ - and $S$-methyl mandelate}

The proposed strategy of covalent unfolding and refolding of immobilized enzymes has been quite useful, but some doubts remain as to the real form of the reactivated enzyme structure and whether this form may be obtained throughout a series of reactivation cycles. The ester $p$-NPB is very easily hydrolyzed, and in many of the published papers it has been the only substrate considered. We therefore evaluated the immobilized enzymes after different treatments in the hydrolysis of a more complex substrate, the two isomers of the chiral $R$ - and $S$-methyl mandelate. The results are summarized in Table 1 . 
Table 1 Activity of different biocatalysts versus $R$ - or $S$-methyl mandelate $(50 \mathrm{mM})$ at $\mathrm{pH} 7$ and $25^{\circ} \mathrm{C}$. Experiments were performed as described in Section 2. The activity $(V)$ is given in $\mu$ moles of substrate hydrolyzed per min and per mg of immobilized enzyme

\begin{tabular}{|c|c|c|c|}
\hline BIOCATALYST & $V_{R \text {-methyl mandelate }}$ & $V_{S \text {-methyl mandelate }}$ & $V_{R} / V_{S}$ \\
\hline OCGLXCALB & $83 \pm 4.2$ & $42 \pm 2.1$ & 2.0 \\
\hline OCGLXCALB $^{a}$ cycle 1 & $57 \pm 2.9$ & $21.1 \pm 1.1$ & 2.7 \\
\hline OCGLXCALB $^{a}$ cycle 3 & $51.2 \pm 2.7$ & $19.7 \pm 1$ & 2.6 \\
\hline OCGLXCALB $^{b}$ cycle 1 & $53 \pm 2.7$ & $23 \pm 1.2$ & 2.3 \\
\hline OCGLXCALB $^{b}$ cycle 3 & $49.3 \pm 2.5$ & $20 \pm 1$ & 2.5 \\
\hline GLXCALB & $23.7 \pm 1.2$ & $11.3 \pm 0.6$ & 2.1 \\
\hline GLXCALB $^{a}$ cycle 1 & $19.1 \pm 1$ & $7.6 \pm 0.4$ & 2.5 \\
\hline GLXCALB $^{a}$ cycle 3 & $17.2 \pm 0.9$ & $7.1 \pm 0.4$ & 2.4 \\
\hline GLXCALB $^{b}$ cycle 1 & $17.1 \pm 0.9$ & $7.6 \pm 0.4$ & 2.3 \\
\hline GLXCALB $^{b}$ cycle 1 & $16.3 \pm 0.7$ & $7.2 \pm 0.4$ & 2.3 \\
\hline OCGLXTLL & $0.034 \pm 0.002$ & $0.031 \pm 0.002$ & 1.1 \\
\hline OCGLXTLL $^{a}$ cycle 1 & $0.017 \pm 0.001$ & $0.011 \pm 0.001$ & 1.5 \\
\hline OCGLXTLL $^{a}$ cycle 3 & $0.015 \pm 0.001$ & $0.009 \pm 0.001$ & 1.7 \\
\hline OCGLXTLL $^{b}$ cycle $1^{1}$ & $0.019 \pm 0.002$ & $0.012 \pm 0.001$ & 1.6 \\
\hline OCGLXTLL $^{b}$ cycle 3 & $0.018 \pm 0.002$ & $0.010 \pm 0.001$ & 1.8 \\
\hline BrCNTLL & $0.0088 \pm 0.0002$ & $0.0058 \pm 0.0002$ & 1.5 \\
\hline BrCNTLL $^{a}$ cycle 1 & $0.0047 \pm 0.0001$ & $0.0031 \pm 0.0001$ & 1.5 \\
\hline BrCNTLL $^{a}$ cycle 3 & $0.0046 \pm 0.0001$ & $0.0031 \pm 0.0001$ & 1.5 \\
\hline BrCNTLL $^{b}$ cycle 1 & $0.0045 \pm 0.0001$ & $0.0032 \pm 0.0001$ & 1.4 \\
\hline BrCNTLL $^{b}$ cycle 3 & $0.0041 \pm 0.0001$ & $0.0028 \pm 0.0001$ & 1.5 \\
\hline
\end{tabular}

${ }^{a}$ The biocatalyst was submitted to unfolding and refolding for the number of cycles indicated. ${ }^{b}$ The biocatalyst was submitted to inactivation by incubation in solvent (90\% DMF for CALB, 80\% dioxane for TLL), and unfolding and refolding steps, during the number of cycles indicated.

It is clear that the percentage of activity recovered using these more complex substrates was lower than that using $p$-NPB, and it also decreased between cycles 1 and 3 of unfolding and refolding, suggesting that the structure of the enzyme obtained in each reactivation cycle might differ from that in the previous cycle. Thus, OCGLX-CALB decreased in activity versus $R$-methyl mandelate to less than $70 \%$ of that in the first cycle, and after three cycles the activity fell to $60 \%$. Inactivation of the enzyme by incubation in $90 \%$ DMF did not significantly alter the result. Using GLX-CALB, in distinction to $p$-NPB, an initial decrease in activity to $80 \%$ now became clear. After the third cycle, only $70 \%$ of the initial activity was recovered. OCGLX-TLL decreased in activity to $50 \%$ in the first cycle of unfolding and refolding, and to a similar value if the enzyme was first inactivated with dioxane; after three cycles the activity had recovered slightly in both cases. BrCN-TLL preparations exhibited a very similar behavior.

Using CALB, the decrease in enzyme activity was usually higher than with the worst substrate (the $S$-isomer), and this produced an increase in CALB enantiospecificity after applying the reactivation strategy. OCGLX-CALB increased the ratios of the rate of hydrolysis between $R$ - and $S$-isomers from 2 to a maximum 2.7. It may be expected that the less than full recovery of the enzyme structure had a greater impact on its activity than that of the less suitable substrate.

This result agrees with the discrepancy between the results obtained in the unfolding and refolding of unaltered and inactivated enzyme preparations, and indicates that even if this basic strategy may be useful in reactivating enzymes used in simple reactions with good substrates, the situation becomes more complex if the enzymes are used with poorer substrates, since the achievement of an identically functional enzyme structure is not fulfilled.

\section{Discussion}

The strategy of unfolding and refolding by incubation in high concentrations of organic solvents may be used to reactivate inactivated enzymes, provided these are covalently attached to the support. This is possible even using a support whose surface is full of large hydrophobic octyl groups, which presents problems in the unfolding and refolding of the enzyme and gives lower percentages of activity recovery. However, enzyme activity and stability in these supports is already quite adequate, and the possibility of incomplete reactivation may further increase the usefulness of the immobilization method compared to the use of pure octyl supports (with which reactivation is not possible) or covalent preparations (where activity and stability are lower).

However, the results indicated that it was not a simple matter to recover the initial enzyme structure, or at least an identical structure after each reactivation cycle, and this may be a problem if the enzyme is used in reactions in which the enzyme determines not only the reaction rate but also the quality of the product (e.g. in the resolution of racemic mixtures). This also suggests that in studies involving the reactivation of enzymes, it is not enough simply to use an easily modifiable substrate; some substrates barely recognized by the enzymes may be used as probes during the actual reactivation of the enzyme molecules.

The lack of full recovery of enzyme activity, or at least a similar level of activity, during the succeeding cycles suggests that we had not obtained exactly the same structure during each refolding cycle. It appears that simpler substrates allow a higher enzyme conformational change before the activity starts to decrease. The failure in recovering a similar activity in each reactivation cycle may have a number of explanations. Firstly, an enzyme submitted to unfolding and refolding may not be fully renatured, even in its free form, and this may give rise to the enzyme having a different conformation, and different functional properties as a result. ${ }^{52}$ Moreover, Illanes' group has reported that reactivated immobilized penicillin $\mathrm{G}$ acylase biocatalysts exhibit a significant alteration in kinetic parameters compared to the initial enzyme preparations, although they did not establish whether this new enzyme structure was always obtained during successive reactivation cycles, since only one cycle was studied. ${ }^{53}$

It has also been reported that if unfolding and refolding strategies are applied to immobilized enzymes and the distance between enzyme molecules is not large enough to prevent interaction between unfolded enzyme structures, the unfolded state thus having a larger volume that the folded state, these interactions may prevent the correct refolding of the enzyme. ${ }^{25}$ This problem cannot occur in covalent preparations, in which 
the immobilization is very slow and the loading of the support quite low, but immobilization of lipases on OCGLX is so rapid that a crown of enzyme molecules packed together can be formed in the outer part of the support particle. In fact, it has been shown that even using very low enzyme loadings, the distance between enzyme molecules immobilized on octyl supports is so short that they may be cross-linked by a molecule as small as glutaraldehyde. ${ }^{54,55}$

It is therefore very likely that OCGLX preparations may create problems in refolding, for instance interactions with the octyl groups, steric problems in the movement of the protein chain generated by the support, and the close proximity of other unfolded enzyme molecules that can cause unwelcome interactions. However, it is also clear that enzyme activity may be completely destroyed by enzyme distortion caused by incubation in solvents and unfolded by incubation in guanidine, and a high percentage of enzyme activity is recovered after refolding in an aqueous medium.

These initial promising results show that the reactivation of lipases immobilized on OCGLX supports opens up new lines of research. It will be necessary to attempt to shortcut some of the problems found in this research in the application of unfolding and refolding strategies as a method of reactivating lipases immobilized on this interesting support. Optimization of the reactivation medium (e.g., using detergents, or thiolated compounds) may give a further improvement in these promising results.

\section{Acknowledgements}

We are grateful for the support provided by the MINECO of Spanish Government, CTQ2013-41507 R. The predoctoral fellowships for Ms Rueda (Colciencias, Colombian Government) and Mr dos Santos (CNPq, Brazil) are also acknowledged. The authors wish to thank Mr Ramiro Martínez (Novozymes, Spain) for kindly supplying the enzymes used in the research. The kind help and comments given by Dr Ángel Berenguer (Instituto de Materiales, Universidad de Alicante) are gratefully acknowledged.

\section{References}

1 Y. Ni, D. Holtmann and F. Hollmann, ChemCatChem, 2014, 6, 930-943.

2 N. Tibrewal and Y. Tang, Annu. Rev. Chem. Biomol. Eng., 2014, 5, 347-366.

3 A. Wells and H.-P. Meyer, ChemCatChem, 2014, 6, 918-920. 4 J. H. Schrittwieser and V. Resch, RSC Adv., 2013, 3, 17602.

5 M. T. Reetz, J. Am. Chem. Soc., 2013, 135, 12480-12496.

6 G. W. Zheng and J. H. Xu, Curr. Opin. Biotechnol., 2011, 22, 784-792.

7 R. N. Patel, ACS Catal., 2011, 1, 1056-1074.

8 H. E. Schoemaker, D. Mink and M. G. Wubbolts, Science, 2003, 299, 1694-1697.

9 P. V. Iyer and L. Ananthanarayan, Process Biochem., 2008, 43, 1019-1032.
10 K. M. Polizzi, A. S. Bommarius, J. M. Broering and J. F. Chaparro-Riggers, Curr. Opin. Chem. Biol., 2007, 11, 220-225.

11 V. G. H. Eijsink, S. GÅseidnes, T. V. Borchert and B. Van Den Burg, Biomol. Eng., 2005, 22, 21-30.

12 S. S. Wong and L. J. C. Wong, Enzyme Microb. Technol., 1992, 14, 866-874.

13 R. C. Rodrigues, Á. Berenguer-Murcia and R. FernandezLafuente, Adv. Synth. Catal., 2011, 353, 2216-2238.

14 U. Guzik, K. Hupert-Kocurek and D. Wojcieszyńska, Molecules, 2014, 19, 8995-9018.

15 V. Stepankova, S. Bidmanova, T. Koudelakova, Z. Prokop, R. Chaloupkova and J. Damborsky, ACS Catal., 2013, 3, 2823-2836.

16 R. C. Rodrigues, C. Ortiz, Á. Berenguer-Murcia, R. Torres and R. Fernández-Lafuente, Chem. Soc. Rev., 2013, 42, 6290-6307. 17 E. T. Hwang and M. B. Gu, Eng. Life Sci., 2013, 13, 49-61.

18 R. Fernandez-Lafuente, Enzyme Microb. Technol., 2009, 45, 405-418.

19 A. Kumar and P. Venkatesu, Chem. Rev., 2012, 112, 42834307.

20 R. A. Sheldon and S. van Pelt, Chem. Soc. Rev., 2013, 42, 6223-6235.

21 D. A. Cowan and R. Fernandez-Lafuente, Enzyme Microb. Technol., 2011, 49, 326-346.

22 K. Hernandez and R. Fernandez-Lafuente, Enzyme Microb. Technol., 2011, 48, 107-122.

23 C. Garcia-Galan, Á. Berenguer-Murcia, R. FernandezLafuente and R. C. Rodrigues, Adv. Synth. Catal., 2011, 353, 2885-2904.

24 V. V. Mozhaev and K. Martinek, Enzyme Microb. Technol., 1982, 4, 299-309.

25 O. Romero, J. M. Guisán, A. Illanes and L. Wilson, J. Mol. Catal. B: Enzym., 2012, 74, 224-229.

26 C. A. Godoy, B. de las Rivas, D. Bezbradica, J. M. Bolivar, F. López-Gallego, G. Fernandez-Lorente and J. M. Guisan, Enzyme Microb. Technol., 2011, 49, 388-394.

27 J. M. Bolivar, J. Rocha-Martin, C. Godoy, R. C. Rodrigues and J. M. Guisan, Process Biochem., 2010, 45, 107-113.

28 J. M. Guisán, G. Alvaro, R. Fernandez-Lafuente, C. M. Rosell, J. L. Garcia and A. Tagliani, Biotechnol. Bioeng., 1993, 42, 455-464.

29 R. C. Rodrigues, J. M. Bolivar, A. Palau-Ors, G. Volpato, M. A. Z. Ayub, R. Fernandez-Lafuente and J. M. Guisan, Enzyme Microb. Technol., 2009, 44, 386-393.

30 R. C. Rodrigues, J. M. Bolivar, G. Volpato, M. Filice, C. Godoy, R. Fernandez-Lafuente and J. M. Guisan, J. Biotechnol., 2009, 144, 113-119.

31 R. C. Rodrigues, C. A. Godoy, M. Filice, J. M. Bolivar, A. Palau-Ors, J. M. Garcia-Vargas, O. Romero, L. Wilson, M. A. Z. Ayub, R. Fernandez-Lafuente and J. M. Guisan, Process Biochem., 2009, 44, 641-646.

32 C. Cambillau, S. Longhi, A. Nicolas and C. Martinez, Curr. Opin. Struct. Biol., 1996, 6, 449-455.

33 A. M. Brzozowski, U. Derewenda, Z. S. Derewenda, G. G. Dodson, D. M. Lawson, J. P. Turkenburg, F. Bjorkling, 
B. Huge-Jensen, S. A. Patkar and L. Thim, Nature, 1991, 351, 491-494.

34 K. K. Kim, H. K. Song, D. H. Shin, K. Y. Hwang and S. W. Suh, Structure, 1997, 5, 173-185.

35 K. E. Jaeger, S. Ransac, H. B. Koch, F. Ferrato and B. W. Dijkstra, FEBS Lett., 1993, 332, 143-149.

36 M. Cygler and J. D. Schrag, Biochim. Biophys. Acta, 1999, 1441, 205-214.

37 R. Verger, Trends Biotechnol., 1997, 15, 32-38.

38 J. Uppenberg, M. T. Hansen, S. Patkar and T. A. Jones, Structure, 1994, 2, 293-308.

39 K. Hernandez, C. Garcia-Galan and R. Fernandez-Lafuente, Enzyme Microb. Technol., 2011, 49, 72-78.

40 C. Carrasco-López, C. Godoy, B. de las Rivas, G. FernándezLorente, J. M. Palomo, J. M. Guisán, R. FernándezLafuente, M. Martínez-Ripoll and J. A. Hermoso, J. Biol. Chem., 2009, 284, 4365-4372.

41 U. Derewenda, L. Swenson, R. Green, Y. Wei, S. Yamaguchi, R. Joerger, M. J. Haas and Z. S. Derewenda, Protein Eng., 1994, 7, 551-557.

42 A. Bastida, P. Sabuquillo, P. Armisen, R. FernándezLafuente, J. Huguet, J. M. Guisán, R. Fernandez-Lafuente, J. Huguet and J. Guisan, Biotechnol. Bioeng., 1998, 58, 486493.

43 E. A. Manoel, J. C. S. dos Santos, D. M. G. Freire, N. Rueda and R. Fernandez-Lafuente, Enzyme Microb. Technol., 2015, 71, 53-57.
44 R. Fernandez-Lafuente, P. Armisén, P. Sabuquillo, G. Fernández-Lorente and J. M. Guisán, Chem. Phys. Lipids, 1998, 93, 185-197.

45 N. Rueda, J. C. S. dos Santos, R. Torres, C. Ortiz, O. Barbosa and R. Fernandez-Lafuente, $R S C A d v ., 2015$, 5, 11212-11222.

46 E. M. Anderson, K. M. Larsson and O. Kirk, Biocatal. Biotransform., 1998, 16, 181-204.

47 V. Gotor-Fernández, E. Busto and V. Gotor, Adv. Synth. Catal., 2006, 348, 797-812.

48 R. Fernandez-Lafuente, J. Mol. Catal. B: Enzym., 2010, 62, 197-212.

49 J. Guisán, Enzyme Microb. Technol., 1988, 10, 375-382.

50 C. Mateo, O. Abian, M. Bernedo, E. Cuenca, M. Fuentes, G. Fernandez-Lorente, J. M. Palomo, V. Grazu, B. C. C. Pessela, C. Giacomini, G. Irazoqui, A. Villarino, K. Ovsejevi, F. Batista-Viera, R. Fernandez-Lafuente and J. M. Guisán, Enzyme Microb. Technol., 2005, 37, 456-462.

51 R. M. Blanco, J. J. Calvete and J. Guisán, Enzyme Microb. Technol., 1989, 11, 353-359.

52 M. Hattori, A. Ametani, Y. Katakura, M. Shimizu and S. Kaminogawa, J. Biol. Chem., 1993, 268, 22414-22419.

53 O. Romero, E. Araya, A. Illanes and L. Wilson, J. Mol. Catal. B: Enzym., 2014, 104, 70-74.

54 O. Barbosa, C. Ortiz, Á. Berenguer-Murcia, R. Torres, R. C. Rodrigues and R. Fernandez-Lafuente, RSC Adv., 2014, 4, 1583.

55 O. Barbosa, R. Torres, C. Ortiz and R. Fernandez-Lafuente, Process Biochem., 2012, 47, 766-774. 